\title{
Vitamin D Levels among Hospitalized and Non-Hospitalized COVID-19 Patients in Dr. M. Djamil General Hospital Padang
}

\author{
Harika Putra, Efrida, and Rismawati Yaswir
}

\section{ABSTRACT}

Coronavirus Disease 2019 (COVID-19) causes immune system dysregulation and an exaggerated systemic inflammatory response. Vitamin $D$ acts as an immunomodulator that enhances the immunity defense. Degression of vitamin D levels affect the severity of COVID-19 infection Our case-control study compared the vitamin D levels between hospitalized and non-hospitalized COVID-19 patients at RSUP dr. M. Djamil, Padang from February to September 2020. Serum vitamin D levels were categorized as deficiency if the level was less than $20 \mathrm{ng} / \mathrm{mL}$ based on the Chemiluminescent Microparticle Immunoassay. The hospitalized group consisted of moderate to critical COVID-19 patients, whereas the nonhospitalized group consisted of the asymptomatic and mild COVID-19 patients according to the Indonesian Ministry of Health Guidelines. Data analysis were performed using $\mathrm{T}$-test and $\mathrm{Chi}$-square with a significant $\mathrm{p}$ value of less than 0.05 . The results showed that most subjects were women between 21-60 years. The mean level of vitamin $D(\mathrm{ng} / \mathrm{mL})$ in the hospitalized group was lower than in the non-hospitalized group $(15.5 \pm 7.72$ vs. $19.2 \pm 14.30 ; 95 \%$ CI $-9.509-2.167 ; p=0.213$ ). Vitamin $D$ deficiency was found more among hospitalized group than the non-hospitalized group, but not statistically significant $(71 \%$ vs. $64.5 \%, p=0.566)$. It indicated the role of vitamin $D$ in preventing immune system hyperactivation causing COVID-19 cytokine storm. This study concluded no difference in vitamin D levels among the study groups. Nevertheless, further research on vitamin D is needed to determine its role and benefits against COVID-19 infection.

Keywords: COVID-19, cytokine storm, inflammation, vitamin D deficiency.
Submitted : November 3, 2021

Published : December 10, 2021

ISSN: 2593-8339

DOI: 10.24018 /ejmed.2021.3.6.1131

H. Putra*

Clinical Pathology Residency Program, Faculty of Medicine, Andalas University, Dr. M. Djamil Hospital, Padang, Indonesia.

(e-mail: drharikaputra@gmail.com) Efrida

Department of Clinical Pathology and Laboratory Medicine, Faculty of Medicine, Andalas University, Dr. M. Djamil Hospital, Padang, Indonesia.

\section{R. Yaswir}

Department of Clinical Pathology and Laboratory Medicine, Faculty of Medicine, Andalas University, Dr. M. Djamil Hospital, Padang, Indonesia.

*Corresponding Author

\section{INTRODUCTION}

Coronavirus Disease 2019 (COVID-19) is a newly discovered infectious disease caused by the Severe Acute Respiratory Syndrome Coronavirus-2 (SARS-CoV-2) [1]. The SARS-CoV-2 virus exhibits the ability to evade the immune defense, so it can avoid the immune system which plays a significant role in viral clearance during the ongoing infection process [2]. This mechanism causes a strong inflammatory response that enhances immune system hyperactivation and cytokine storm. This pathological process results in serious damage to the host, leading to acute respiratory distress syndrome (ARDS) and mortality. Vitamin D, known for its immunomodulatory effect, has been reported to suppress this process, thereby assumed to prevent the severity of COVID-19 infection [1]-[3]. Vitamin D metabolite is an endogenous steroid hormone synthesized through the effects of ultraviolet radiation on the skin. It also can be exogenously derived through daily supplements and dietary sources [4]. Deficiency of vitamin D is one of the global nutritional health problems, affecting $5.9-13 \%$ of the worldwide population [5]. Vitamin D provides an essential role in many physiological functions. Several studies emphasized the effect of vitamin $\mathrm{D}$ in the modulation of the immune system, which includes the T-cells, B-cells, macrophages, neutrophils, and dendritic cells [6]. Vitamin D exhibits effective anti-inflammatory and immunomodulatory properties [7]. Recent data reported the effect of vitamin D supplementation, which can inhibit the replication of the SARS-CoV-2 virus by optimizing the function of the innate and adaptive immune systems [8]-[10].

The severity and mortality of COVID-19 differ widely and are influenced by various risk factors. Nutritional deficiency is a risk factor that can affect the immune system. Several studies have reported the association between the low vitamin D levels with the clinical outcomes of COVID-19 patients. Raharusuna et al. reported that vitamin D insufficiency and deficiency increased the COVID-19 mortality risk by 7.63 times and 10.12 times, respectively [11]. Macaya et al. reported vitamin D deficiency as a predictor for the severity risk of COVID-19. The group of COVID-19 patients with a level of vitamin D less than $20 \mathrm{ng} / \mathrm{mL}$ increased the disease severity by 3.2 times compared to the control group [12].

The clinical criteria guidelines issued by the Indonesian Ministry of Health currently classify the COVID-19 severity into asymptomatic, mild, moderate, severe, and critical symptoms. The guidelines suggest that asymptomatic and mildly symptoms patients undergo self-isolation at home, 
whereas patients with moderate, severe, and critical symptoms are hospitalized to achieve better-optimized care. Early detection of clinical manifestations will provide sufficient opportunity for appropriate management and treatment to prevent the severity and death of COVID-19 [13]. We aim to determine vitamin D levels among hospitalized and non-hospitalized COVID-19 patients at RSUP Dr. M. Djamil, Padang.

\section{METHODS}

A case-control study was performed involving 62 registered COVID-19 patients at Dr. M. Djamil General Hospital, Padang, Indonesia, from February to September 2020. The diagnosis of COVID-19 was established according to the medical history of confirmed SARS-CoV-2 oronasopharyngeal result using real-time Polymerase Chain Reaction (PCR) test performed at the Diagnostic Laboratory and Research Center for Infectious Diseases, Faculty of Medicine, Andalas University. All subjects aged between 1860 years were included consecutively. Exclusion criteria were the history of bone diseases (rickets, osteoporosis), liver disease, and vitamin D malabsorption (chronic pancreatitis, cystic fibrosis, ileocecal resection). The subjects were distributed into two groups, i.e., the case group of 31 hospitalized patients with moderate, severe, or critical COVID-19 symptoms, and the control group of 31 nonhospitalized patients with asymptomatic or mild COVID-19 symptoms [13], [14].

Vitamin D (25-hydroxyvitamin D) analysis was performed on the serum blood sample taken at the patient's first visit. The specimens were refrigerated at the temperature of $-200^{\circ} \mathrm{C}$ until the minimum sample size was met and examined using the Chemiluminescent Microparticle Immunoassay (CMIA; Abbott Diagnostics, Lake Forest, IL, USA) technique. The measurement range for vitamin D was 3.0-150.0 ng/mL. Classification of vitamin D status was determined based on the 25-hydroxyvitamin $\mathrm{D}$ serum levels $<20 \mathrm{ng} / \mathrm{mL}$ as deficiency status, $20-29 \mathrm{ng} / \mathrm{mL}$ as insufficiency status, and $\geq$ $30 \mathrm{ng} / \mathrm{mL}$ as sufficiency status [15]. The sampling procedure was carried out based on standard operating procedures after gaining written informed consent from the patient. The Ethical Committee of the Faculty of Medicine, Andalas University and Dr. M. Djamil General Hospital Padang permitted the study protocol.

The analysis was presented according to IBM Statistical Package for Social Sciences 21.0 (SPSS; IBM Corp., Armonk, NY, USA). Numerical variables were presented mean \pm standard deviation and categorical variables were presented in numbers and percentages. Chi-square analysis was used to compare the categorical data between two groups. The Kolmogorov-Smirnov test was used to confirm the normal distribution of the numerical variables. Parametric (independent T-test) or non-parametric tests (Mann-Whitney test) were used to compare the ordinal data between two groups, according to the normality of data. The p-value less than 0.05 was considered statistically significant.

\section{RESUlTS}

The study population consisted of hospitalized and nonhospitalized groups with a total of 31 subjects in each group (Table I). Most of the subjects were women, both in the hospitalized and non-hospitalized groups (67.7\% vs. 58.1\%, respectively). The mean age of hospitalized patients was $43.48 \pm 12.41$ years and the non-hospitalized patients was $36.87 \pm 8.60$ years. There was a statistically significant difference in age between the two groups $(p=0.018)$. The mean level of vitamin D in the hospitalized group was lower than in the non-hospitalized group; however, it was not statistically significant $(15.5 \pm 7.72$ vs. $19.2 \pm 14.30 ; 95 \%$ CI $9.509-2.167 ; p=0.213)$. Fig. 1 shows the mean of vitamin $\mathrm{D}$ levels between the two groups.

Vitamin D deficiency was found more in the hospitalized group than in the non-hospitalized group. However, the statistical difference in vitamin D status between the two groups did not show a significant result (71\% vs. $64.5 \%, p=$ $0.566)$. Fig. 2 shows the percentage of vitamin D deficiency in the hospitalized and non-hospitalized groups.

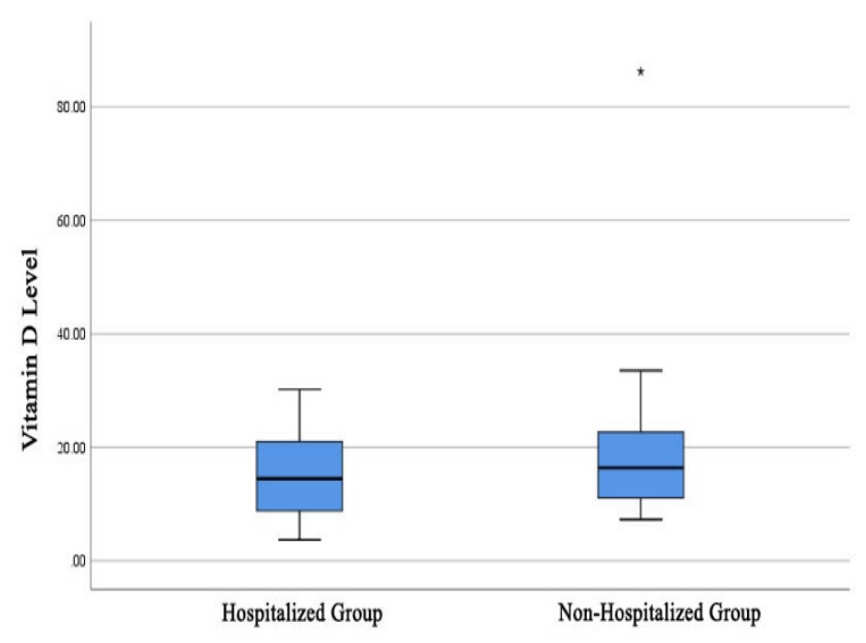

Fig. 1. The mean of vitamin D level between the hospitalized and nonhospitalized groups.

TABLE I: DEMOGRAPHIC AND VITAMIN D CHARACTERISTICS OF THE STUDY POPULATION

\begin{tabular}{cccc}
\hline \hline Variable & $\begin{array}{c}\text { Hospitalized } \\
\text { Group }(\mathrm{n}=31)\end{array}$ & $\begin{array}{c}\text { Non- } \\
\text { Hospitalized } \\
\text { Group }(\mathrm{n}=31)\end{array}$ & $p$-value \\
\hline \hline Gender, n (\%) & $10(32.3)$ & $13(41.9)$ & 0.430 \\
Male & $21(67.7)$ & $18(58.1)$ & \\
Female & $43.48 \pm 12.41$ & $36.87 \pm 8.60$ & 0.018 \\
Age, mean \pm SD (years) & $15.5 \pm 7.72$ & $19.2 \pm 14.3$ & 0.213 \\
Vitamin D, mean \pm SD & & & $0.566^{*}$ \\
(ng/mL) & $22(71.0)$ & $20(64.5)$ & \\
Vitamin D status, n (\%) & $7(22.5)$ & $8(25.8)$ & \\
Deficiency & $2(6.5)$ & $3(9.7)$ & \\
Insufficiency & Sufficiency &
\end{tabular}

* Mann-Whitney test was used because the data did not meet the requirements for Chi-square test analysis; SD: standard deviation. 
A

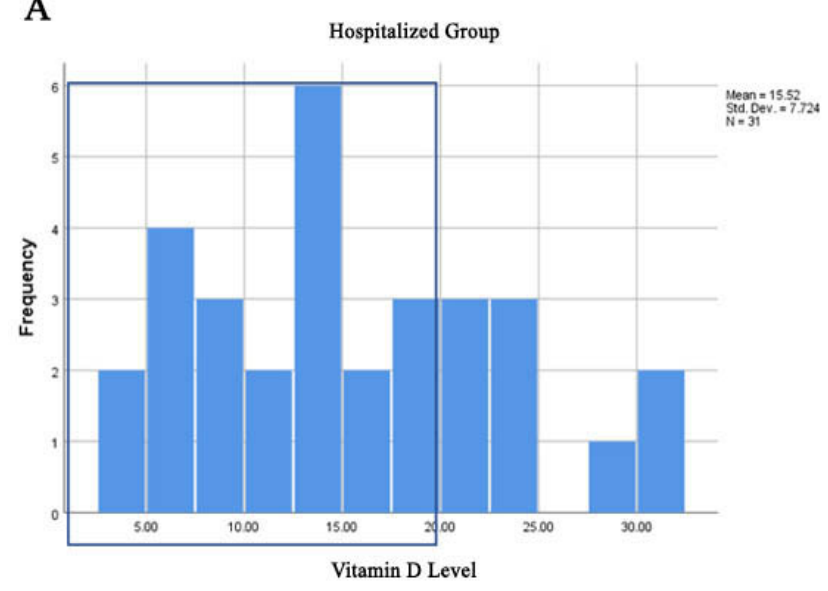

B

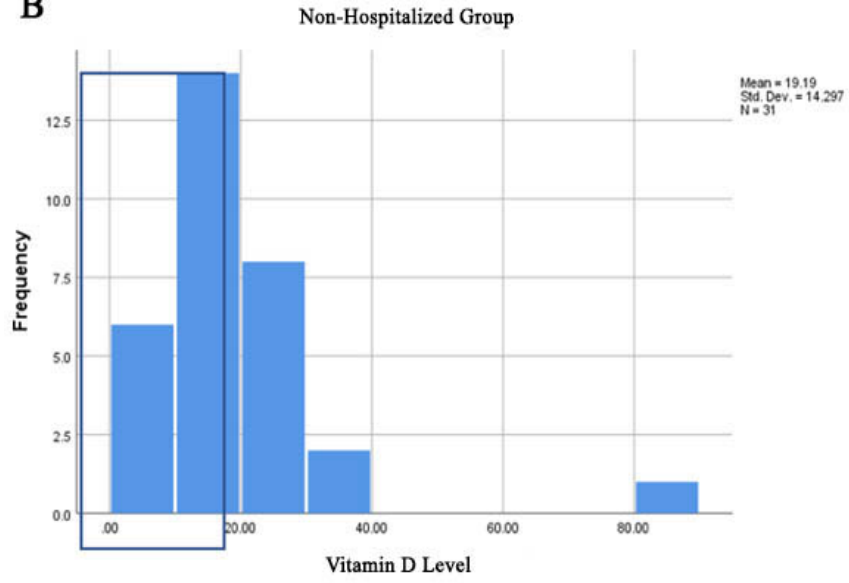

Fig. 2. Histogram of vitamin D deficiency between the hospitalized (A) and non-hospitalized groups (B).

\section{DISCUSSION}

Our study compared the vitamin D levels between the hospitalized and non-hospitalized COVID-19 patients. Our findings support the findings from Merzon et al., which reported lower vitamin D levels among those who were confirmed with COVID-19 compared to the controls (18.38 ng/mL vs. $20.45 \mathrm{ng} / \mathrm{mL}$ ) [16]. This study also revealed nearly two-folds increased likelihood of hospitalization in COVID-19 patients with vitamin D levels less than $30 \mathrm{ng} / \mathrm{mL}$; however, after adjusting several demographic characteristics, statistical analysis results were found to be insignificant. Furthermore, multivariate analysis on demographic variables showed nearly three-folds increased risk of hospitalization was only significant in patients over 50 years of age [16]. In our study, the mean age of the subjects was predominantly less than 50 years. This may explain the insignificant difference in vitamin D levels between these groups.

Pinzon et al. reported that about $90 \%$ of positive COVID19 patients in Yogyakarta, Indonesia, were deficient and 10\% were insufficient in vitamin D level [17]. Hernández et al. reported lower alteration of vitamin D levels in COVID-19 patients than the population-based controls $(13.8 \mathrm{ng} / \mathrm{mL}$ vs. $20.9 \mathrm{ng} / \mathrm{mL} ; p<0.0001$, respectively) [18].

However, in a retrospective cohort conducted by Hastie et al., no significant difference of hospitalization rates among COVID-19 patients with insufficient (adjusted IRR $=1.06$; 95\% CI $0.89-1.26 ; p=0.525$ ) or deficient (adjusted IRR =
$1.10 ; 95 \%$ CI $0.88-1.37 ; p=0.404)$ vitamin D level, compared to those with sufficient vitamin D level [19]. On the other hand, Radujkovic et al. reported the significant differences in the median (interquartile range) of vitamin D levels between the inpatient and outpatient subjects. This study involved most hospitalized patients with age older than 60 years old $(61 \%)$ [20].

Vitamin D deficiency has been identified in the morbidity and mortality associated with COVID-19. It also tends to be more common in patients with severe and critical severity who require intensive care [16]-[21]. Vitamin D is responsible in the immune system as an immunomodulator that regulates proinflammatory cytokines. This mechanism also plays a role in the early infection of COVID-19, indicated by an increase in the phagocytic capacity of immune cells and the expression of proinflammatory cytokines. Vitamin D also induces the synthesis of antimicrobial peptides, including cathelicidin and $\beta$ defensin. In a later stage, vitamin $\mathrm{D}$ modulates the inflammatory response by decreasing the expression of proinflammatory cytokines through the induction of M2 macrophages and the differentiation of Th2 and Treg cells. This process can prevent the occurrence of a cytokine storm, which is the cause of the severity and death of COVID-19 [12], [16]. Vitamin D holds down the transcription of renin and consequently angiotensin expression, also increases angiotensinconverting enzyme 2 (ACE2) expression that is possibly regenerating normal physiological concentration of ACE2 downregulated by the SARS-CoV-2 virus [22].

In this study, there were no significant differences in vitamin D levels and status according to the disease severity based on self-isolation or hospitalization status. Previous research conducted at Dr. M. Djamil General Hospital Padang reported that vitamin D deficiency occurred in $76 \%$ of the research population [23]. This suggests that the population in this study may have been vitamin $\mathrm{D}$ deficient prior to infection of COVID-19. Specific research on vitamin $\mathrm{D}$ status in the older age group may be needed because of the significant differences in COVID-19 clinical outcomes in this population. Another limitation in this study includes that only one measurement was done, considering a case-control study design. Thus, further research should be carried out using a cohort design, allowing multiple data collection in different stages of the disease, in order to determine the more precise role and benefits of vitamin D against COVID-19 infection.

\section{CONCLUSION}

Vitamin D deficiency is frequent in COVID-19 patients, eventhough the levels and status did not differ between the hospitalized and non-hospitalized patients. Further research is needed with a prospective design considering additional analysis on other confounding factors that can affect the regulation of vitamin D in COVID-19 infection.

\section{CONFLICT OF INTEREST}

Authors declare that they do not have any conflict of interest. 


\section{REFERENCES}

[1] Ali N. Role of vitamin D in preventing of COVID-19 infection, progression, and severity. Journal of Infection and Public Health. 2020; 13(10): 1373-1380.

[2] Turrubiates-Hernández FJ, Sánchez-Zuno GA, González-Estevez G, Hernández-Bello J, Macedo-Ojeda G, Muñoz-Valle JF. Potential immunomodulatory effects of vitamin $\mathrm{D}$ in the prevention of severe coronavirus disease 2019: An ally for Latin America (Review). International Journal of Molecular Medicine. 2021; 47(4): 32.

[3] Cutolo M, Paolino S, Smith V. Evidence for a protective role of vitamin D in COVID-19. RMD Open. 2020; 6: e001454.

[4] Pusparini. Defisiensi vitamin D terhadap penyakit. Indonesian Journal of Clinical Pathology and Medical Laboratory. 2014; 21(1): 90-95. Indonesian.

[5] Amrein K, Scherkl M, Hoffmann M, Neuwersch-Sommeregger S, Köstenberger M, Berisha AT, et al. Vitamin D deficiency 2.0: an update on the current status worldwide. European Journal of Clinical Nutrition. 2020; 74: 1498-1513.

[6] Di Rosa M, Malaguarnera M, Nicoletti F, Malaguarnera L. Vitamin D3: a helpful immuno-modulator. Immunology. 2011; 134(2): 123-139.

[7] Dankers W, Colin EM, van Hamburg JP, Lubberts E. Vitamin D in Autoimmunity: Molecular Mechanisms and Therapeutic Potential. Frontiers in Immunology. 2017; 7: 697.

[8] Grant WB, Lahore H, McDonnell SL, Baggerly CA, French CB, Aliano $\mathrm{JL}$, et al. Evidence that vitamin D supplementation could reduce risk of influenza and COVID-19 infections and deaths. Nutrients. 2020; 12(4): 988.

[9] Annweiler G, Corvaisier M, Gautier J, Dubée V, Legrand E, Sacco G, et al. Vitamin D supplementation associated to better survival in hospitalized frail elderly COVID-19 patients: the GERIA-COVID quasi-experimental study. Nutrients. 2020; 12(11): 3377.

[10] Ling SF, Broad E, Murphy R, Pappachan JM, Pardesi-Newton S, Kong $\mathrm{MF}$, et al. High-dose cholecalciferol booster therapy is associated with a reduced risk of mortality in patients with COVID-19: a crosssectional multi-centre observational study. Nutrients. 2020; 12(12): 3799.

[11] Raharusuna P, Priambada S, Budiarti C, Agung E, Budi C. Patterns of COVID-19 mortality and vitamin D: an indonesian study. SSRN Electronic Journal. 2020: 1-14.

[12] Macaya F, Espejo C, Valls A, Ortiz AF, Castillo JG, Martin J, et al. Interaction between age and vitamin D deficiency in severe COVID-19 infection. Nutricion Hospitalaria. 2020; 37(5): 1039-1042.

[13] Kementerian Kesehatan Republik Indonesia. Pedoman pencegahan dan pengendalian coronavirus disease (COVID-19) revisi Ke-5. Kementerian Kesehatan Republik Indonesia. Jakarta. 2020; 1-214. Indonesian.

[14] Edis Z, Bloukh SH. Vitamin D deficiency: main factors affecting the serum 25-hydroxyvitamin d ([25(OH)D]) status and treatment options. International Journal of Research. 2016; 3(1): 197-210.

[15] Abbott Laboratories. Architect 25-OH Vitamin D, B5P020 25-OH Vitamin D 5P02 G5-6832/R03e, Lake Forest, Illinois, USA. 2020:1-8.

[16] Merzon E, Tworowski D, Gorohovski A, Vinker S, Golan Cohen A, Green I, et al. Low plasma $25(\mathrm{OH})$ vitamin D level is associated with increased risk of COVID-19 infection: an Israeli population-based study. FEBS J. 2020; 287(17): 3693-3702.

[17] Pinzon RT, Angela, Pradana AW. Vitamin D deficiency among patients with COVID-19: case series and recent literature review. Troical Medical Health. 2020; 48: 102.

[18] Hastie CE, Pell JP, Sattar N. Vitamin D and COVID-19 infection and mortality in UK Biobank. European Journal of Nutrition. 2021; 60(1): 545-548.

[19] Hernández JL, Nan D, Fernandez-Ayala M, García-Unzueta M, Hernández-Hernández MA, López-Hoyos M, et al. Vitamin D status in hospitalized patients with SARS-CoV-2 infection. Journal of Clinical Endocrinology \& Metabolism. 2021; 106(3): e1343-e1353.

[20] Radujkovic A, Hippchen T, Tiwari-Heckler S, Dreher S, Boxberger M, Merle U. Vitamin D deficiency and outcome of COVID-19 patients. Nutrients. 2020; 12(9): 2757.

[21] Wang MX, Gwee SXW, Pang J. Micronutrients deficiency, supplementation and novel coronavirus infections-a systematic review and meta-analysis. Nutrients. 2021; 13(5): 1589.

[22] Bourgonje AR, Abdulle AE, Timens W, Hillebrands JL, Navis GJ, Gordijn SJ, et al. Angiotensin-converting enzyme 2 (ACE2), SARSCoV-2 and the pathophysiology of coronavirus disease 2019 (COVID19). Journal of Pathology. 2020; 251(3): 228-248.

[23] Efrida, Yaswir R, Rofinda ZD. Hubungan vitamin D dengan kadar adiponektin, Hs-CRP, dan profil lipid pada subjek berat badan berlebih di RSUP Dr. M. Djamil Padang. Jurnal Kesehatan Andalas. 2018. Indonesian. 